\title{
Highly efficient solvent-free synthesis of pyranopyrazoles by a Brønsted-acidic ionic liquid as a green and reusable catalyst
}

\author{
JAVAD EBRAHIMI $^{\mathrm{a}, *}$, ALI MOHAMMADI $^{\mathrm{b}, *}$, VAHID PAKJOO $^{\mathrm{c}}$, EHSAN BAHRAMZADE $^{\mathrm{c}}$ \\ and AMIR HABIBI ${ }^{\mathrm{C}}$ \\ ${ }^{a}$ Young Researchers Club, Islamic Azad University, Mashhad Branch, P.O. Box 9187147578, Mashhad, Iran \\ ${ }^{b}$ Department of Chemistry, Faculty of Sciences, Ferdowsi University of Mashhad, P.O. Box 91775, \\ Mashhad, Iran \\ ${ }^{c}$ Department of Chemistry, Islamic Azad University, Mashhad Branch, P.O. Box 9187147578, Mashhad, Iran \\ e-mail: javad_ebrahimi@ymail.com; a.mohammdy62@yahoo.com
}

MS received 7 September 2011; revised 2 April 2012; accepted 6 June 2012

\begin{abstract}
A simple, green and efficient protocol for synthesis of dihydropyrano[2,3-c]pyrazole derivatives is developed by a four component reaction of various benzaldehydes, ethyl acetoacetate, hydrazine hydrate and malononitrile in the presence of 3-methyl-1-(4-sulphonic acid)butylimidazolium hydrogen sulphate $\left[\left(\mathrm{CH}_{2}\right)_{4} \mathrm{SO}_{3} \mathrm{HMIM}\right]\left[\mathrm{HSO}_{4}\right]$, an acidic ionic liquid and as a catalyst, under solvent-free conditions. The key advantages of this process are high yields, shorter reaction times, easy work-up, purification of products by non-chromatographic method and the reusability of the catalyst.
\end{abstract}

Keywords. Pyranopyrazoles; solvent-free synthesis; multicomponent reaction; ionic liquid; heterogeneous catalysts.

\section{Introduction}

Multicomponent reactions (MCRs) have drawn great interest enjoying an outstanding status in modern organic synthesis and medicinal chemistry because they are one-pot processes bringing together three or more components and show high atom economy and high selectivity. ${ }^{1,2}$ MCRs have great contribution in convergent synthesis of complex and important organic molecules from simple and readily available starting materials, and have emerged as powerful tools for drug discovery. ${ }^{3,4}$ The pyranopyrazole nucleus is a fertile source of biologically important molecules. Compounds containing this moiety have many pharmacological properties and play important roles in biochemical processes. They are well-known as antimicrobial, insecticidal and antiinflammatory compounds. Furthermore, these compounds showed molluscicidal activity and was identified as a screening kit for Chk1 kinase inhibitor. ${ }^{5}$ During the last few years, some methods were introduced for the synthesis of these compounds. Otto had proposed the first synthesis of the dihydropyrano[2,3-c]-pyrazoles in 1974, via the base catalysed cycloaddition of 4-aryliden-5-pyrazolone. ${ }^{6}$ Pyranopyrazole is also synthesized from the reaction

*For correspondence between 3-methyl-1-phenylpyrazolin-5-one and tetracyano ethylene. In addition, weak bases can also be used for this Michael-type cyclization. ${ }^{7}$ Other recent methods for the synthesis of pyranopyrazoles include a three-component condensation between $\mathrm{N}$ methylpiperidone, pyrazolin-5-one and malononitrile in absolute ethanol, ${ }^{8}$ a two-component reaction involving pyran derivatives and hydrazine hydrate, ${ }^{9}$ use of piperidine as a base in water, ${ }^{10} \mathrm{~N}$-methylmorpholine in ethanol, ${ }^{11}$ microwave irradiation ${ }^{12}$ and also solvent-free conditions. ${ }^{13}$

In the recent years, ionic liquids have become a powerful alternative to conventional molecular organic solvents due to their particular properties, such as undetectable vapour pressure and the ability to dissolve many organic and inorganic substances. ${ }^{14}$ In addition, the ionic liquids are readily recycled and tunable to specific chemical tasks. One type is Brønsted-acidic task-specific ionic liquids (BAILs). Among these, ionic liquids possessing $\mathrm{HSO}_{4}$ as a counteranion find a broad application in organic synthesis, acting as both solvents and catalysts. Recently, immobilization processes involving acidic ionic liquids on solids supports have been designed. ${ }^{15-21}$ The heterogenization of catalysts and reagents can offer important advantages in handling, separation and reuse procedures. Based on economic criteria, it is desirable to minimize the amount 

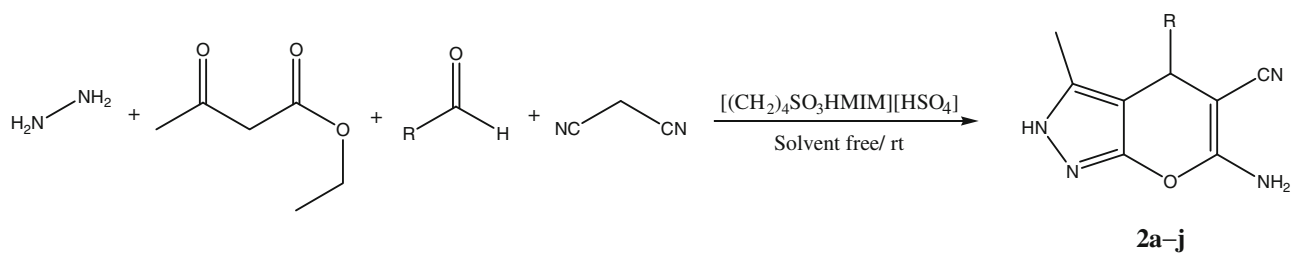

Figure 1. $\left[\left(\mathrm{CH}_{2}\right)_{4} \mathrm{SO}_{3} \mathrm{HMIM}\right]\left[\mathrm{HSO}_{4}\right]$ catalysed synthesis of pyranopyrazoles.

of ionic liquid utilized in a potential process. Immobilized acidic ionic liquids have been used as novel solid catalysts for a wide spectrum of reactions. ${ }^{22-26}$ With these considerations in mind and our interest in the development of new synthetic method in heterocyclic chemistry, we introduce here a facile method for synthesis of biologically active dihydropyrano[2,3-c]pyrazoles systems.

In this work, we report the solvent-free synthesis of dihydropyrano[2,3-c]-pyrazoles via four component reaction of various benzaldehydes, ethyl acetoacetate, hydrazine hydrate and malononitrile in the presence of 3-methyl-1-(4-sulphonic acid)butylimidazolium hydrogen sulphate $\left[\left(\mathrm{CH}_{2}\right)_{4} \mathrm{SO}_{3} \mathrm{HMIM}\right]\left[\mathrm{HSO}_{4}\right]$, an acidic ionic liquid as a catalyst. We examined a wide variety of benzaldehydes with various substituents to establish the catalytic importance of this catalyst for this reaction (figure 1).

\section{Experimental}

Melting points were measured with an Electrothermal 9100 apparatus. IR spectra were recorded with a Varian 3100 FTIR spectrometer. CHN analyses were performed on Exeter Analytical Inc. 'Model CE-400 CHN Analyzer'. ${ }^{1} \mathrm{H}$ and ${ }^{13} \mathrm{C}$ NMR spectra were recorded with a BRUKER DRX-400 AVANCE spectrometer at $298^{\circ} \mathrm{K}$ and $75.47 \mathrm{MHz}$, respectively. NMR spectra were obtained on solutions in DMSO- $\mathrm{d}_{6}$. All the products are known compounds, ${ }^{7,10-13}$ which were characterized by IR and ${ }^{1} \mathrm{H}$ NMR spectral data and their melting points were compared with literature reports.

\subsection{Preparation and reusability of the acidic ionic liquid}

3-Methyl-1-(4-sulphonic acid)butylimidazolium hydrogen sulphate $\left[\left(\mathrm{CH}_{2}\right)_{4} \mathrm{SO}_{3} \mathrm{HMIM}\right]\left[\mathrm{HSO}_{4}\right]$ was prepared according to the literature. ${ }^{27}$ When the acidic ionic liquid was used in the reaction and the reaction was completed, appropriate amounts of $\mathrm{EtOH}(96 \%)$ was added. The ionic liquid solved in EtOH and was sepa-
Table 1. Reuse of the acidic ionic liquid for synthesis of $1 \mathrm{a}$.

\begin{tabular}{lcc}
\hline Entry & Time (min) & Yield (\%) \\
\hline 1 & 30 & 85 \\
2 & 30 & 85 \\
3 & 30 & 82 \\
4 & 30 & 80 \\
\hline
\end{tabular}

rated by filtration. The filtrate was concentrated in vacuo to remove the ethanol and the acidic ionic liquid remains. The recycled catalyst was employed consecutively for four reactions and no significant loss in its efficiency was observed (table 1).

\subsection{General procedure for preparation of $\mathbf{2} \mathbf{a}-\mathbf{j}$}

At first, substituted benzaldehyde $(1 \mathrm{mmol})$ and $\left[\left(\mathrm{CH}_{2}\right)_{4} \mathrm{SO}_{3} \mathrm{HMIM}\right]\left[\mathrm{HSO}_{4}\right](0.25 \mathrm{mmol})$ as a catalyst, was mixed for $5 \mathrm{~min}$ then ethyl acetoacetate $(1 \mathrm{mmol})$, hydrazine hydrate $(1 \mathrm{mmol})$ and malononitrile $(1 \mathrm{mmol})$ was added to this mixture and stirred at room temperature for $30 \mathrm{~min}$. The reaction was monitored by TLC. After completion of the reaction, appropriate amounts of $\mathrm{EtOH}(96 \%)$ were added and the mixture was stirred for $10 \mathrm{~min}$ then, the catalyst was separated by filtration. The precipitation was washed by cold ethanol and after that was crystallized from hot ethanol to afford the pure products.

\subsection{Selected spectral data}

2.3a 6-Amino-4-(4-methoxyphenyl)-3-methyl-2,4dihydropyrano[2,3-c]pyrazole-5-carbonitrile (2d): $\mathrm{Mp} 171-173^{\circ} \mathrm{C}$. FTIR $\left(\mathrm{KBr}, \mathrm{cm}^{-1}\right): v=3483.51(\mathrm{NH})$, 3256.70 and $3105.54\left(\mathrm{NH}_{2}\right), 2191.93(\mathrm{CN}), 1612.09$ $(\mathrm{C}=\mathrm{N}), 1583.27(\mathrm{C}=\mathrm{C}) ;{ }^{1} \mathrm{H}$ NMR $(400 \mathrm{MHz}$, DMSO$\left.\mathrm{d}_{6}\right): \delta=1.79(\mathrm{~s}, 3 \mathrm{H}, \mathrm{CH} 3), 3.75(\mathrm{~s}, 3 \mathrm{H}, \mathrm{O}-\mathrm{CH} 3)$, 4.50 (s, 1H, C-4 pyran), 6.85 (d, 2H, p-anisyl-H), 6.88 (d, 2H, p-anisyl-H), 7.09 (s, 2H, NH2), 12.08 (s, 1H, $\mathrm{NH}) ;{ }^{13} \mathrm{C}$ NMR $\left(75 \mathrm{MHz}, \mathrm{DMSO}-\mathrm{d}_{6}\right): \delta=9.8,35.5$, 54.7, 57.6, 117.5, 105.7, 110.3, 113.75, 136.5, 142.28, 
154.74, 155.72, 160.68; Anal. Calcd for $\mathrm{C}_{15} \mathrm{H}_{14} \mathrm{~N}_{4} \mathrm{O}_{2}$ : C, 63.82; H, 5.00; N, 19.85. Found: C, 63.24; H, 4.87; N, 19.81 .

$2.3 \mathrm{~b}$ 6-Amino-4-(4-methylphenyl)-3-methyl-2,4dihydropyrano[2,3-c]pyrazole-5-carbonitrile (2j): Mp $175-177^{\circ} \mathrm{C}$. FTIR $\left(\mathrm{KBr}, \mathrm{cm}^{-1}\right): v=3448.78(\mathrm{NH})$, 3418.4 and $3353.51\left(\mathrm{NH}_{2}\right), 2188.78(\mathrm{CN}), 1624.91$ $(\mathrm{C}=\mathrm{N}), 1579.37(\mathrm{C}=\mathrm{C}) ;{ }^{1} \mathrm{H}$ NMR $(400 \mathrm{MHz}, \mathrm{DMSO}-$ $\left.\mathrm{d}_{6}\right): \delta=1.8$ (s, 3H, CH3), 2.28 (s, 3H, Ar-CH3), 4.52 (s, 1H, C-4 pyran), 6.85 (d, 2H, p-tolyl-H), 7.00 (d, 2H, p-tolyl-H), 7.18 (s, 2H, NH2), 12.09 (s, 1H, NH); ${ }^{13} \mathrm{C}$ NMR $\left(75 \mathrm{MHz}, \mathrm{DMSO}-\mathrm{d}_{6}\right): \delta=9.9,20.7,36.7$, 40.1, 78.3, 97.4, 120.7, 127.2, 128.6, 135.4, 140.9, 154.7, 160.6; Anal. Calcd for $\mathrm{C}_{15} \mathrm{H}_{14} \mathrm{~N}_{4} \mathrm{O}$ : C, 67.65; H, 5.30; N, 21.04. Found: C, 67.15; H, 5.17; N, 21.00.

\section{Results and discussion}

Several methods are used in the synthesis of these dihydropyrano[2,3-c]pyrazole derivatives. In addition, the synthesis of these heterocycles has been usually carried out in polar organic solvents such as water, ethanol, DMF and DMSO leading to complex isolation and recovery procedures. These processes also generate waste containing catalyst and solvent, which have to be recovered, treated and disposed of. ${ }^{7,28}$ The toxicity and volatile nature of many organic solvents, particularly chlorinated hydrocarbons that are widely used in huge amounts for organic reactions have posed a serious threat to the environment. ${ }^{29}$ Thus, design of solvent-free catalytic reaction has received tremendous attention in recent times in the area of green synthesis. ${ }^{30}$

The choice of a solvent is a crucial factor for multicomponent reactions. So at the first step we looked into the solvent effect for this reaction. We tested the reaction in some protic and aprotic solvents such as ethanol, water and acetonitrile in the presence of $\left[\left(\mathrm{CH}_{2}\right)_{4} \mathrm{SO}_{3} \mathrm{HMIM}\right]\left[\mathrm{HSO}_{4}\right]$ as a catalyst. The reaction in the aprotic solvent had satisfying performance but in the aprotic solvent (acetonitrile) efficiency was poor, even after $24 \mathrm{~h}$. Also the reaction was carried out at the solvent-free conditions. By omitting the solvent, the productivity of the reaction was better and additionally, the reaction time decreased. The related results are given in table 2. Hence, in the next steps we have used the solvent free conditions for synthesis of substituted pyranopyrazoles.

Apart from the solvent, the efficiency of the multicomponent reactions is mainly affected by the amount of catalyst and the reaction time. In the next stage for getting the best conditions, we started the condensation
Table 2. Effects of different solvents on the reaction productivity $^{\mathrm{a}}$.

\begin{tabular}{lcccc}
\hline Entry & Catalyst $^{\mathrm{b}}$ & Solvent & Time & Yield (\%) \\
\hline 1 & Acidic ionic liquid & - & $0.5 \mathrm{~h}$ & 75 \\
2 & Acidic ionic liquid & Water & $1 \mathrm{~h}$ & 67 \\
3 & Acidic ionic liquid & Ethanol & $1 \mathrm{~h}$ & 55 \\
4 & Acidic ionic liquid & Acetonitrile & $24 \mathrm{~h}$ & - \\
\hline
\end{tabular}

a4-Chlorobenzaldehyde/ethylacetoacetat/hydrazine hydrate/ malonitrile $(1: 1: 1: 1 \mathrm{mmol})$

b0.15 mmol

Table 3. Optimization of amount of catalyst for synthesis of pyranopyrazol from 4-chlorobenzaldehyde ${ }^{\mathrm{a}}$.

\begin{tabular}{lccc}
\hline Entry & $\begin{array}{c}\text { Catalyst } \\
(\mathrm{mmol})\end{array}$ & $\begin{array}{c}\text { Time } \\
(\mathrm{min})\end{array}$ & Yield \\
\hline 1 & 0.05 & 30 & 50 \\
2 & 0.10 & 30 & 65 \\
3 & 0.15 & 30 & 75 \\
4 & 0.20 & 30 & 81 \\
5 & 0.25 & 30 & 85 \\
6 & 0.30 & 30 & 85 \\
\hline
\end{tabular}

a-Chlorobenzaldehyde/ethylacetoacetat/hydrazine hydrate/ malonitrile $(1: 1: 1: 1 \mathrm{mmol})$

Table 4. Synthesis of substituted pyranopyrazoles using $\left[\left(\mathrm{CH}_{2}\right)_{4} \mathrm{SO}_{3} \mathrm{HMIM}\right]\left[\mathrm{HSO}_{4}\right](0.25 \mathrm{mmol})$ as a catalyst under solvent-free conditions.

\begin{tabular}{lcccc}
\hline & & & \multicolumn{2}{c}{$\mathrm{Mp} /{ }^{\circ} \mathrm{C}$} \\
\cline { 4 - 5 } Product $^{\mathrm{a}}$ & $\mathrm{R}$ & ${\text { Yields }(\%)^{\mathrm{b}}}^{n}$ & Found & Reported \\
\hline $\mathbf{2 a}$ & $4-\mathrm{ClPh}$ & 85 & $173-175$ & $174-175^{7}$ \\
$\mathbf{2 b}$ & $3-\mathrm{ClPh}$ & 80 & $157-158$ & $158-160^{7}$ \\
$\mathbf{2 c}$ & $2-\mathrm{ClPh}$ & 80 & $145-147$ & $145-146^{7}$ \\
$\mathbf{2 d}$ & $4-\mathrm{MeOPh}$ & 85 & $171-173$ & $170-172^{7}$ \\
$\mathbf{2 e}$ & $\mathrm{Ph}$ & 80 & $166-168$ & $167-169^{7}$ \\
$\mathbf{2 f}$ & $4-\mathrm{BrPh}$ & 80 & $181-183$ & $180-183^{7}$ \\
$\mathbf{2 g}$ & $3-\mathrm{BrPh}$ & 80 & $177-179$ & - \\
$\mathbf{2 h}$ & $4-\mathrm{NO}{ }_{2} \mathrm{Ph}$ & 90 & $193-194$ & $192-194^{7}$ \\
$\mathbf{2 i}$ & $3-\mathrm{NO}_{2} \mathrm{Ph}$ & 85 & $190-193$ & $190-192^{7}$ \\
$\mathbf{2 j}$ & $4-\mathrm{MePh}_{\mathbf{2}}^{\mathbf{j}}$ & 90 & $175-177$ & $175-176^{7}$
\end{tabular}

${ }^{a}$ All the isolated products were characterized on the basis of their physical properties and IR, ${ }^{1} \mathrm{H}$ - and ${ }^{13} \mathrm{C}$-NMR spectral analysis and by direct comparison with authentic materials ${ }^{\mathrm{b}}$ Isolated yields

of 4-chloro benzaldehyde ( $1 \mathrm{mmol})$, ethyl acetoacetate ( $1 \mathrm{mmol})$, hydrazine hydrate $(1 \mathrm{mmol})$, malononitrile $(1 \mathrm{mmol})$ and $\left[\left(\mathrm{CH}_{2}\right)_{4} \mathrm{SO}_{3} \mathrm{HMIM}\right]\left[\mathrm{HSO}_{4}\right](0.05 \mathrm{mmol})$, as a catalyst at room temperature for $30 \mathrm{~min}$, which led to low yield $(55 \%)$ of the product. To enhance the yield of the desired product, the amount of catalyst was 
increased to $0.3 \mathrm{mmol}$. With increasing the amount of the catalyst, the productivity of the reaction increased. As indicated in table 3, maximum yield was obtained $(85 \%)$ when the reaction was loaded with $0.25 \mathrm{mmol}$ of the catalyst. A further increasing of catalyst loading did not affect the yield.

After optimizing the conditions, we applied this catalyst for synthesis of substituted pyranopyrazoles by using different aromatic aldehydes with a wide range of ortho-, meta- and para-substitutions under solvent-free classical heating conditions to establish the catalytic importance of $\left[\left(\mathrm{CH}_{2}\right)_{4} \mathrm{SO}_{3} \mathrm{HMIM}\right]\left[\mathrm{HSO}_{4}\right]$ for this reaction. The corresponding results are given in table 4 . We found that the reaction proceeded efficiently by either electron-releasing or electron-withdrawing substituents on aryl ring of aldehyde.

Possible mechanism for the $\left[\left(\mathrm{CH}_{2}\right)_{4} \mathrm{SO}_{3} \mathrm{HMIM}\right]-$ $\left[\mathrm{HSO}_{4}\right]$ catalysed synthesis of substituted pyranopyrazoles has been proposed in figure 2. In summary, this paper describes a convenient and efficient process for the solvent-free synthesis of substituted pyranopyrazoles through the four components coupling of aldehydes, ethyl acetoacetate, hydrazine hydrate, malononitrile using $\left[\left(\mathrm{CH}_{2}\right)_{4} \mathrm{SO}_{3} \mathrm{HMIM}\right]\left[\mathrm{HSO}_{4}\right]$ as a catalyst. Reaction profile is very clean and no side products are formed. All the synthesized pyranopyrazoles have been characterized on the basis of elemental and spectral studies. We believe that this procedure is
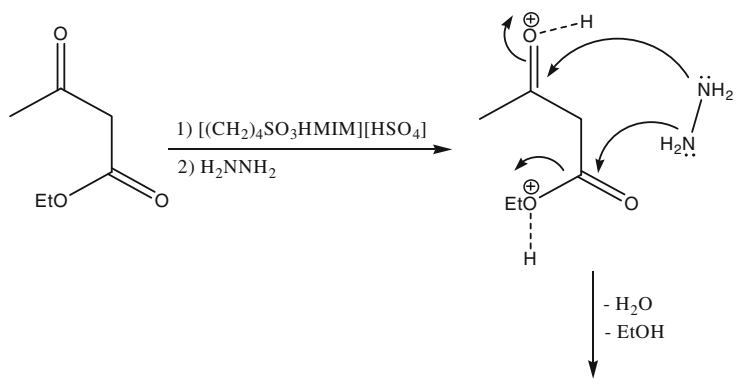<smiles>CC1=NNC(=O)C1</smiles>

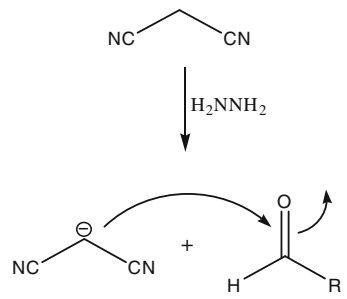

$\searrow \mathrm{H}_{2} \mathrm{NNH}_{2}$
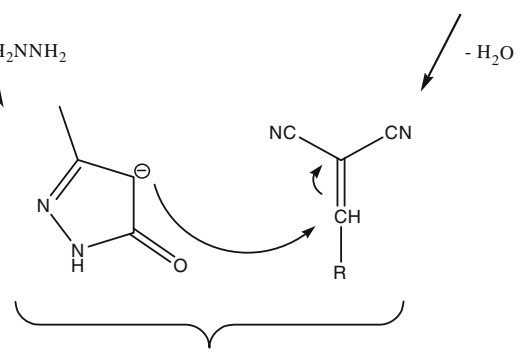

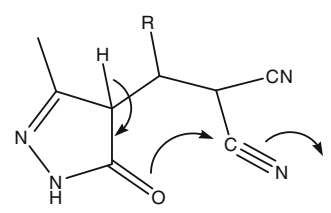<smiles>[R]C1C(C#N)=C(N)Oc2n[nH]c(C)c2C1[13CH](C)[14CH3]</smiles>

Figure 2. Probable mechanism for the formation of substituted pyranopyrazoles using $\left[\left(\mathrm{CH}_{2}\right)_{4} \mathrm{SO}_{3} \mathrm{HMIM}\right]\left[\mathrm{HSO}_{4}\right]$ as a catalyst. 
convenient, economic, and a user-friendly process for the synthesis substituted pyranopyrazoles of biological and medicinal importance.

\section{Conclusion}

We have been able to introduce an efficient and environmentally friendly approach for the synthesis of biologically active substituted pyranopyrazoles via condensation of various aromatic aldehydes, ethyl acetoacetate, hydrazine hydrate, malononitrile using $\left[\left(\mathrm{CH}_{2}\right)_{4} \mathrm{SO}_{3} \mathrm{HMIM}\right]\left[\mathrm{HSO}_{4}\right]$ as a catalyst. High yields, easy work-up, purification of compounds by nonchromatographic method (crystallization only) and the reusability of the catalyst are the key advantages of this method.

\section{References}

1. D'Souza D M and Mueller T J J 2007 Chem. Soc. Rev. 361095

2. Domling A 2006 Chem. Rev. 10617

3. Tempest P A 2005 Curr. Opin. Drug. Discov. Dev. 8 776

4. Kalinski C, Lemoine H, Schmidt J, Burdack C, Kolb J, Umkehrer M and Ross G 2008 Synlett. 244007

5. Shaabani A, Sarvary A, Rezayan A and Keshipour S 2009 Tetrahedron $\mathbf{6 5} 3492$

6. Otto H H 1974 Arch. Pharm. 307444

7. Kanagaraj K and Pitchumani K 2010 Tetrahedron Lett. 513312

8. Shestopalov A M, Emeliyanova Y M, Shestopalov A A, Rodinovskaya L A, Niazimbetova, Z I and Evans D H 2002 Org. Lett. 4423

9. Peng Y, Song G and Dou R 2006 Green Chem. 8573
10. Vasuki G and Kumaravel K 2008 Tetrahedron Lett. 49 5636

11. Lehmann F, Holm M and Laufer S 2008 J. Comb. Chem. 10364

12. Zhou J F, Tu S J, Zhu H Q and Zhi S J 2002 Synth. Commun. 323363

13. Guo S B, Wang S X and Li J T 2007 Synth. Commun. 37 2111

14. Wasserscheid P and Welton T 2007 Ionic liquids in synthesis (Weinheim: Wiley-VCH)

15. Du Y, Tian F and Zhao W 2006 Synth. Commun. 361661

16. Gupta N, Sonu, Kad G L and Singh J 2007 Catal. Commun. 81323

17. Hajipour A R, Rajaei A and Ruoho A E 2009 Tetrahedron Lett. $\mathbf{5 0} 708$

18. Khosropour A R 2008 Can. J. Chem. 86264

19. Wang W, Cheng W, Shao L and Yang J 2008 Catal. Lett. 12177

20. Wasserscheid P, Sesing M and Korth W 2002 Green Chem. 4134

21. Xu D Q, Yang W L, Luo S P, Wang B T, Wu J and Xu Z Y 2007 Eur. J. Org. Chem. 61007

22. Fischer J and Hölderich W F 1999 Appl. Catal. A: Gen. 180435

23. González-Núñez M E, Mello R, Olmos A and Asensio G 2005 J. Org. Chem. 7010879

24. González-Núñez M E, Mello R, Olmos A and Asensio G 2006 J. Org. Chem. 716432

25. Qiao K, Hagiwara H and Yokoyama C 2006 J. Mol. Catal. A: Chem. 24665

26. Sugimura R, Qiao K, Tomida D and Yokoyama C 2007 Catal. Commun. 8770

27. Wang W, Shao L, Cheng W, Yang J and He M 2008 Catal. Commun. 9337

28. Al-matar H M, Khalil K D, Adam A Y and Elnagdi M H 2010 Molecules 156619

29. Maleki B, Azarifar D, vaghei R G, Veisi H, Hojati S F, Gholizadeh M, Salehabadi H and Moghadam M K 2009 Monatsh. Chem. 1401485

30. Nelson W M, Anastas P T and Williamson T C 1998 Green chemistry (Oxford: Oxford University) 